\title{
A TREE-RING BASED LATE SUMMER TEMPERATURE RECONSTRUCTION (AD 1675-1980) FOR THE NORTHEASTERN MEDITERRANEAN
}

\author{
VALERIE TROUET*
}

Laboratory of Tree-Ring Research, University of Arizona, 1215 E. Lowell Street, Tucson, AZ 85721, USA. *Corresponding author: trouet@1trr.arizona.edu.

\begin{abstract}
This article presents a late summer temperature reconstruction (AD 1675-1980) for the northeastern Mediterranean (NEMED) that is based on a compilation of maximum latewood density tree-ring data from 21 high-elevation sites. This study applied a novel approach by combining individual series from all sites into one NEMED master chronology. This approach retains only the series with a strong and temporally robust common signal and it improves reconstruction length. It further improved the regional character of the reconstruction by using as a target averaged gridded instrumental temperature data from a broad NEMED region $\left(38-45^{\circ} \mathrm{N}, 15-25^{\circ} \mathrm{E}\right)$. Cold (e.g. 1740) and warm (e.g. 1945) extreme years and decades in the reconstruction correspond to regional instrumental and reconstructed temperature records. Some extreme periods (e.g. cold 1810s) reflect European-wide or global-scale climate conditions and can be explained by volcanic and solar forcing. Other extremes are strictly regional in scope. For example, 1976 was the coldest NEMED summer over the last 350 years, but was anomalously dry and hot in northwestern Europe and is a strong manifestation of the summer North Atlantic Oscillation (sNAO). The regional NEMED summer reconstruction thus contributes to an improved understanding of regional (e.g. sNAO) vs. global-scale (i.e. external) drivers of past climate variability.
\end{abstract}

Keywords: dendrochronology, temperature reconstruction, northeastern Mediterranean, Balkan Peninsula, North Atlantic Oscillation, maximum latewood density, Maunder minimum, volcanic forcing.

\section{INTRODUCTION}

A growing concern about ongoing and projected climate change and its socioeconomic and environmental implications raises questions about anthropogenic forcing of the climate system and the amplitude and spatial variability of its response (IPCC 2013). A full understanding of the climate system and its long-term variability requires a longer timeframe than instrumental data alone can offer (Hegerl et al. 2006; Jones et al. 2009). Knowledge of preindustrial climate conditions furthermore is necessary to distinguish between anthropogenic and natural drivers of climatic variability. In recent decades, general progress has therefore been made in developing hemispheric-scale climate reconstructions (Mann et al. 2009; Frank et al. 2010) that are largely tree-ring based and reach millennial timescales. Studies at higher spatial resolution, however, are needed to elucidate climate variability patterns and their association with forcings at the regional scale, where changes are arguably most relevant to ecosystems and society (PAGES 2k Consortium 2013).

In the northeastern Mediterranean (NEMED) region, here defined to include part of the central Mediterranean (Italian Peninsula) and the eastern Mediterranean (Balkan Peninsula), an overall warming trend has prevailed in the 20th century, which has been most pronounced since the 1980s (Giles and Flocas 1984; Xoplaki et al. 2003a; Alexandrov et al. 2004; Philandras et al. 2008; Toreti et al. 2010). Summer temperatures are the main contributors to the NEMED warming trend (Kostopoulou and Jones 2005; Nastos et al. 2011; Bartolini et al. 2012), which is expressed as an increase in longer-term (annual- to decadal-scale) averages as well as in the occurrence of extreme events (heat waves). The frequency and duration of summer heat waves is projected to increase dramatically (Founda et al. 2004; Meehl and Tebaldi 2004; Kostopoulou and Jones 2005; Founda and Giannakopoulos 2009) and summer heat that rarely occurred in the late 20th century reference period may become the norm by the middle or end of the 21st century (Lelieveld et al. 2012). Moreover, general circulation model projections consistently project an overall drying of the region (Gibelin and Deque 2003; Hertig et al. 2013) and NEMED has accordingly been identified as a "climatic change hotspot" (Giorgi 2006; Diffenbaugh et al. 2007).

If these projections for future changes in heat stress and water availability are accurate, the socioeconomic and environmental consequences will be significant (Chang et al. 2002; Chenoweth et al. 2011; Lelieveld et al. 2012). Societies in the Mediterranean region are highly dependent on water resources and current vulnerabilities in the region are controlled by seasonal climatic extremes driven by synoptic settings as well as low-frequency climatic change. The projected upsurge of extremely high summer temperatures will have discernable societal impacts, including excess morbidity and mortality (Knowlton et al. 2009), increased energy demand (Smoyer-Tomic et al. 2003; Giannakopoulos et al. 2009), and gradually reduced summer tourism (Alcamo et al. 2007). Intensified heat waves and a reduction in summer precipitation will further affect agricultural production (particularly for rain-fed summer crops; Schroter et al. 2005), forest fire risk (Moriondo et al. 2006), and air quality (Giannakopoulos et al. 2009; Lelieveld et al. 2012). Freshwater scarcity may occur in some areas and will be aggravated by population growth and economic development (Chenoweth et al. 2011). 
The climate change vulnerability of the NEMED region is in stark contrast with the scarcity of reliable proxy records and paleoclimate information in this region (Vakarelov et al. 2001; Xoplaki et al. 2001; Popa and Kern 2009). A network of basin-wide reconstructions of century-scale climate variability exists in the Mediterranean region (Pauling et al. 2006; Nicault et al. 2008), which is based on long instrumental records and proxy data. Wellreplicated tree-ring records have been developed for the Pyrenees (Tardif et al. 2003; Büntgen et al. 2008, 2010a), northern Africa (Esper et al. 2007; Touchan et al. 2008a, 2008b), northeastern Italy (Serre-Bachet 1994), and Turkey (Akkemik and Aras 2005; Touchan et al. 2005a, 2005b, 2007). Historical documentary data are also widely available for the Mediterranean region (Camuffo et al. 2010) and have been used to reconstruct climatic conditions in the Iberian Peninsula (Barriendos and Rodrigo 2006; Dominguez-Castro et al. 2008) and Sicily (Piervitali and Colacino 2001). Additional proxies such as speleothems (Rudzka et al. 2012) and isotopic measurements of annually banded reef corals (Felis and Rimbu 2010) have also provided additional high-resolution information about past climatic information. Nevertheless, proxy data of any origin are scarce in NEMED and in the Balkan Peninsula in particular (Vakarelov et al. 2001; Xoplaki et al. 2001).

I present a NEMED summer temperature reconstruction that is based on a compilation of maximum latewood density (MXD) tree-ring data from high-elevation NEMED sites (Figure 1). At these sites, MXD measurements can contain a much stronger climatic signal than tree-ring width (TRW) (Büntgen et al. 2010a; Trouet et al. 2012), which is typically controlled by a combination of temperature and drought factors at high-elevation sites in Mediterranean environments with wet winters and dry summers.

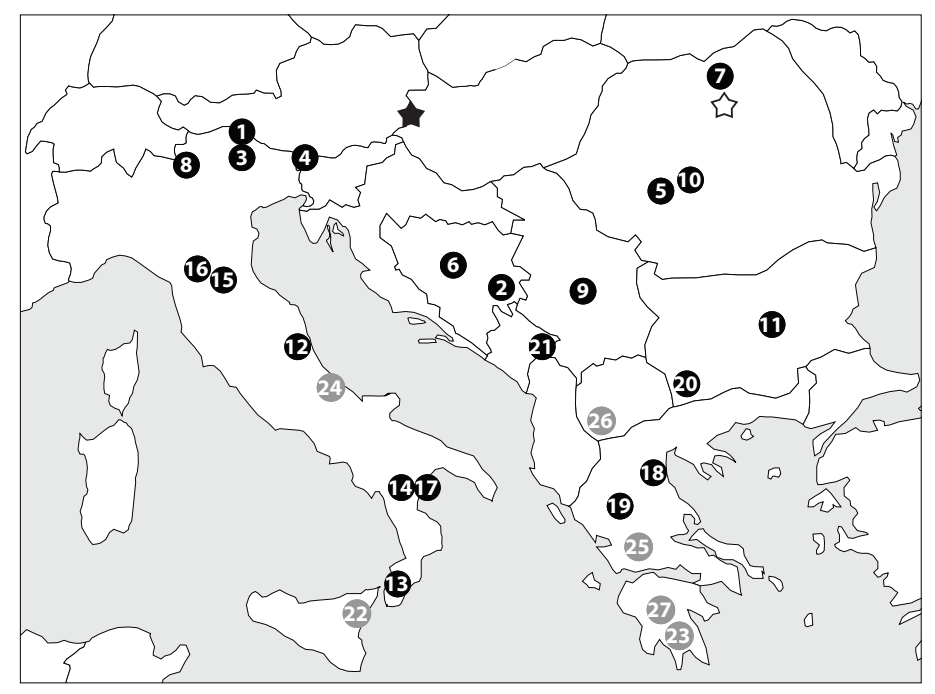

Figure 1. Site location of 27 MXD sites in the NEMED region. Site numbers correspond to the numbers in Table 1. Black circles (1-21) correspond to sites retained for the NEMED regional chronology; gray circles (22-27) were excluded. The black star indicates the location of the Kiss et al. (2011) document record, the white star of the Popa and Kern (2009) tree-ring record (see also Figure 5).
Correlations between TRW series and individual climatic parameters at these sites are often too weak for climate reconstruction purposes (Tardif et al. 2003; Büntgen et al. 2010a; Panayotov et al. 2010; Seim et al. 2012). Despite the large effort necessary to develop MXD chronologies (Schweingruber et al. 1978), this parameter is of relevance because of its pronounced climatic fingerprint and skill as an estimator of past climate variability. The presented tree-ring MXD-based NEMED summer temperature reconstruction spans the last ca. 300 years and puts 20 th century and projected NEMED temperature trends in a longer-term context.

\section{METHODS}

\section{Tree-Ring Data}

This study compiled MXD tree-ring data from 27 NEMED sites (Table 1; Figure 1) that are archived in the International TreeRing Data Bank (ITRDB; http://www.ncdc.noaa.gov/data-access/ paleoclimatology-data/datasets/tree-ring; Grissino-Mayer and Fritts 1997). This compilation contains 11 Picea abies (L.) H. Karst. (PCAB) chronologies, 5 Abies alba Mill. (ABAL) chronologies, 4 Pinus heldreichii H. Christ (PIHE) chronologies, 3 Pinus nigra J. F. Arnold (PINI) chronologies, and 1 chronology each of Pinus peuce Griseb. (PIPE), Abies cephalonica Loudon (ABCE), Abies borisii Mattf. (ABBO), and Picea omorika (Pančić) Purk. (PCOM). Chronologies range in length between 59 years (Sipenski, Bulgaria) and 539 years (Sierra de Crispo, Italy). In a first step, the study analyzed the common variance in the NEMED compilation in a principal component analysis (PCA). Of the original 27 site chronologies, 21 chronologies were retained (in white in Table 1) that exhibited the strongest common variance in the PCA analysis. The individual tree-ring series contributing to these chronologies (484 individual series in total) were then combined in a crossdating exercise to develop one NEMED master chronology. Individual MXD time series were crossdated with the aid of COFECHA software (Grissino-Mayer 2001) and agerelated trends were removed using ARSTAN software from all raw measurements using cubic smoothing splines with a $50 \%$ frequency-response cutoff equal to 150 years (Cook and Peters 1981). A NEMED regional chronology was then calculated by averaging the detrended series using a biweight robust mean (Cook and Peters 1997). Interseries correlation (RBAR) and the estimated population signal (EPS) were calculated for 30-year windows lagged by 15 years to assess the signal strength of the chronology over time (Wigley et al. 1984).

\section{Climate Data}

Early instrumental records (Csernus-Molnár et al. 2014) as well as long time series of instrumental climate data are sporadically available for the NEMED region (e.g. Sofia, Bulgaria, meteorological station: 1887-present; Thessaloniki, Greece, meteorological station: 1892-present), but station data often lack appropriate homogenization (Popa and Kern 2009), are thus not necessarily reliable, and they do not optimally represent climate variability at 
Table 1. Site description for 27 MXD sites in the NEMED region. Sites highlighted in gray were excluded from the final regional NEMED chronology.

\begin{tabular}{|c|c|c|c|c|c|}
\hline \multirow[b]{2}{*}{ No. } & \multirow[b]{2}{*}{ Site } & \multirow[b]{2}{*}{ Country } & \multicolumn{2}{|l|}{ Elevation } & \multirow{2}{*}{$\begin{array}{l}\text { Chronology } \\
\text { length (CE) }\end{array}$} \\
\hline & & & (masl) & Species & \\
\hline 1 & Cortina d'Ampezzo & Italy & 1900 & PCAB & $1660-1981$ \\
\hline \multirow[t]{2}{*}{2} & Jahorina & Bosnia and & 1700 & PCAB & $1736-1981$ \\
\hline & & Herzegovina & & & \\
\hline 3 & Cortina d'Ampezzo & Italy & 1820 & PCAB & $1737-1980$ \\
\hline 4 & Vrsic & Slovenia & 1600 & PCAB & $1757-1981$ \\
\hline 5 & Novaci & Romania & 1650 & PCAB & $1804-1981$ \\
\hline \multirow[t]{2}{*}{6} & Vlasic & Bosnia and & 1600 & PCAB & $1823-1981$ \\
\hline & & Herzegovina & & & \\
\hline 7 & Roncan & Romania & 1480 & PCAB & $1836-1981$ \\
\hline 8 & Blumone & Italy & 1650 & PCAB & $1840-1980$ \\
\hline 9 & Rajinac & Croatia & 1550 & PCAB & $1868-1981$ \\
\hline 10 & Capra & Romania & 1600 & PCAB & $1884-1981$ \\
\hline 11 & Sipenski & Bulgaria & 1300 & PCAB & $1922-1981$ \\
\hline 12 & Bosque di Ceppo & Italy & 1700 & ABAL & $1654-1980$ \\
\hline 13 & Gambarie & Italy & 1850 & ABAL & $1790-1980$ \\
\hline 14 & Mt. Pollino & Italy & 1720 & $\mathrm{ABAL}$ & $1800-1980$ \\
\hline 15 & Falterona & Italy & 1450 & ABAL & $1827-1980$ \\
\hline 16 & Abetone & Italy & 1400 & ABAL & $1846-1980$ \\
\hline 17 & Sierra de Crispo & Italy & 2000 & PIHE & $1441-1980$ \\
\hline 18 & Olympos & Greece & 2250 & PIHE & $1583-1981$ \\
\hline 19 & Katara Pass & Greece & 1750 & PIHE & $1673-1981$ \\
\hline 20 & Vihren & Bulgaria & 2300 & PIHE & $1721-2008$ \\
\hline 21 & Cakor Pass & Montenegro & 1750 & PCOM & $1856-1981$ \\
\hline 22 & Aetna & Italy & 1800 & PINI & $1773-1980$ \\
\hline 23 & Langada & Greece & 1450 & PINI & $1825-1981$ \\
\hline 24 & Mattone & Italy & 1550 & PINI & $1844-1980$ \\
\hline 25 & Panetolikon & Greece & 1350 & $\mathrm{ABBO}$ & $1812-1981$ \\
\hline 26 & Pelister & FYROM & 1900 & PIPE & $1837-1981$ \\
\hline 27 & Menalon & Greece & 1620 & $\mathrm{ABCE}$ & $1832-1981$ \\
\hline
\end{tabular}

$\mathrm{PCAB}=$ Picea abies $; \mathrm{ABAL}=$ Abies alba $; \mathrm{PIHE}=$ Pinus heldreichii $; \mathrm{PCOM}=$ Picea omorika $;$ PINI $=$ Pinus nigra $; \mathrm{ABBO}=$ Abies borisii $;$ PIPE $=$ Pinus peuce $; \mathrm{ABCE}=$ Abies cephalonica .

the regional scale. Therefore, the NEMED tree-ring chronology was compared to a data set of monthly gridded $\left(0.5^{\circ}\right)$ average temperature fields (CRU TS3.1; 1901-2009; Mitchell and Jones 2005) in a spatial correlation map analysis using the KNMI Climate Explorer (http://www.climexp.knmi.nl; Trouet and Van Oldenborgh 2013; Figure 3). The region ( $38-45^{\circ} \mathrm{N}, 15-25^{\circ} \mathrm{E}$; Figure 3) and months (August-September; AS) were selected that generated the strongest correlation coefficients with the NEMED chronology $(\mathrm{r}>0.6 ; 1901-1980 ; \mathrm{p}<0.001)$ and calculated the average value over this region. This CRU TS3.1-based time series was then used in the climate-growth analysis and as a target for reconstruction.

\section{Climate-Growth Analysis}

This study performed a climate-growth analysis for each species in the NEMED tree-ring compilation to verify the common climate signal amongst species before combining them in one master chronology. For this purpose, in a correlation function analysis, species-specific chronologies were compared with regional monthly and seasonal temperature and precipitation averages derived from the CRUTS3.1 gridded data set (see previous). For the four species that were represented by more than one site in the compilation, site chronologies were combined in a PCA analysis and the species-specific PCA1 time series was used [PCAB (1922-1980), ABAL (1846-1980), PIHE (1721-1980), PINI (1844-1980)], representing the strongest common variance amongst the chronologies, in the climate-growth analysis.

\section{Summer Temperature Reconstruction}

The reconstruction process consisted of linear transformation, variance restoration, skill assessment, and uncertainty estimation. Late summer (AS) temperature was reconstructed by linearly transforming (also referred to as scaling) the NEMED tree-ring chronology to match the mean and variance of the instrumental temperature data over the full period of overlap (1901-1980). For this purpose, instrumental temperatures were first calculated as anomalies from the 1961-1990 reference period. To test the skill of the reconstruction, calibration/verification tests, here evaluated using reduction of error (RE) and coefficient of efficiency (CE) statistics (Cook et al. 1994), were calculated on the scaled reconstruction over two equal subperiods of the overlap period (19011940 and 1941-1980). Finally, I merged the most recent instrumental NEMED data (1981-2009), also calculated as anomalies from the 1961-1990 reference period, with the reconstruction.

Uncertainty in the temperature reconstruction arises from the decreasing number of tree-ring series back through time (chronology error) and unexplained variance in the scaling model (calibration error; Esper et al. 2007). ARSTAN software (Cook 1985) was used to estimate the chronology error by bootstrapping (Briffa et al. 1992). Standardized tree-ring measurements for every year were sampled with replacement 1000 times and arithmetic means were calculated. Two-tailed $95 \%$ confidence intervals (CI) were estimated based on the distribution of the bootstrapped mean and the composite plus scaling technique was then applied to the upper and lower limits of the CI for the tree-ring chronology. The calibration error was estimated as two times the standard error (SE) for the full calibration period 1901-1980. Because of the steep decrease in sample replication back in time (323 series in 1901 vs. 17 series in 1675), I calculated SE for 25 -year intervals (starting in 1675) based on scaling models of chronologies that only included the tree-ring series that were present in that 25-year period. Finally, the overall error for the temperature reconstruction was estimated as the square root of the summed and squared calibration and chronology error terms. 
Finally, the NEMED summer temperature reconstruction was compared to regional NEMED summer temperature reconstructions based on historical documentary data (Kiss et al. 2011) and on tree-ring data (Popa and Kern 2009). For these analyses, all proxy time series were smoothed using decadal-scale (20-year) spline functions.

\section{RESULTS}

\section{Species-Specific Climate Growth Analysis}

A PCA analysis per species resulted in a high percentage of variance in the species-specific chronologies explained by the first PCA axis for all species, ranging between $45.4 \%$ for the three PINI chronologies and $73.6 \%$ for the four chronologies. I thus used the PCA1 time series to investigate species-specific climate-growth relationships (Figure 2). For PCAB, ABAL, PIHE, and PCOM, the strongest correlations were found with August and September temperature, resulting in strong positive correlations with August-September (AS) and July-September (JAS) averages ( $\mathrm{r}=$ 0.63 to 0.73 for AS and $r=0.52$ to 0.67 for JAS; $p<0.01$ ). These species also showed strong negative correlations with August precipitation ( $\mathrm{r}=-0.44$ to $-0.54 ; \mathrm{p}<0.01)$. ABCE and PIPE were also significantly positively correlated with August temperature and negatively with August precipitation, but no significant correlation was found with September temperature. The strongest correlation for ABBO MXD was with June temperature $(r=0.47, p<0.01)$ and for PINI with AS precipitation $(r=-0.43 ; \mathrm{p}<0.01)$. Based on these results, I decided to restrict the NEMED MXD compilation to the species that represent the same climate parameter (AS temperature), namely PCAB, ABAL, PIHE, and PCOM (Table 1).
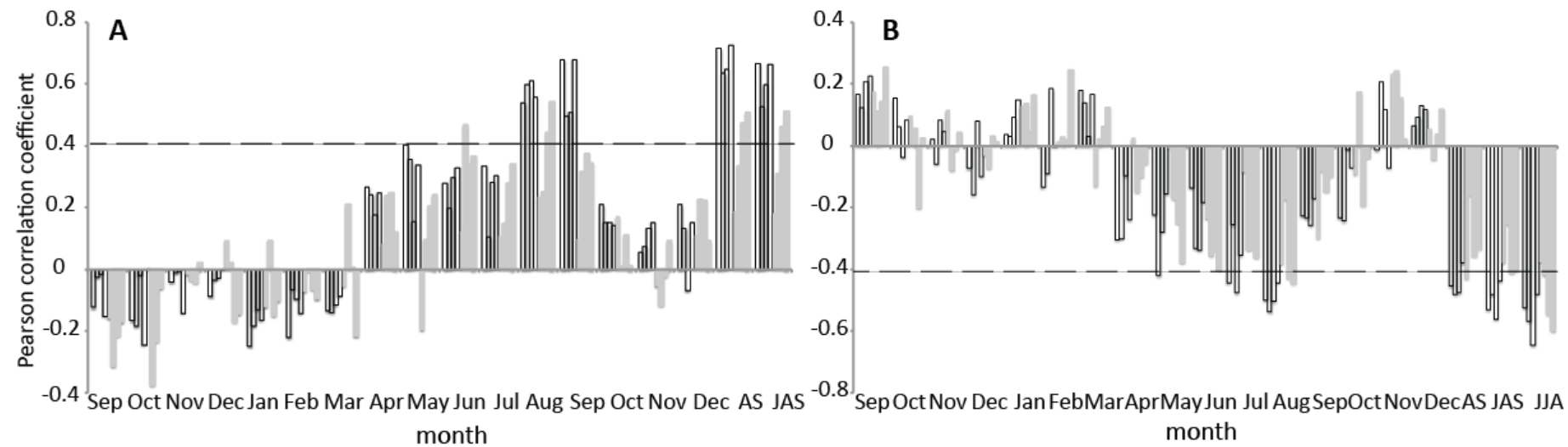

Figure 2. NEMED climate-growth relationships. Correlation between MXD tree-ring chronologies from eight NEMED tree species and monthly values of temperature (A) and precipitation (B) over the common period 1932-1975. Correlations were also calculated for the average of August and September (AS), for the average of July through September (JAS), and for the average of June through August (JJA; precipitation only). From left to right on the bar plot, tree species are PCAB, ABAL, PIHE, PCOM, PINI, ABBO, ABCE, and PIPE. White bars indicate species that are included in the NEMED master chronology; gray bars represent species that were excluded from the chronology. The dashed horizontal line indicates $\mathrm{p}<0.01$ significance level.
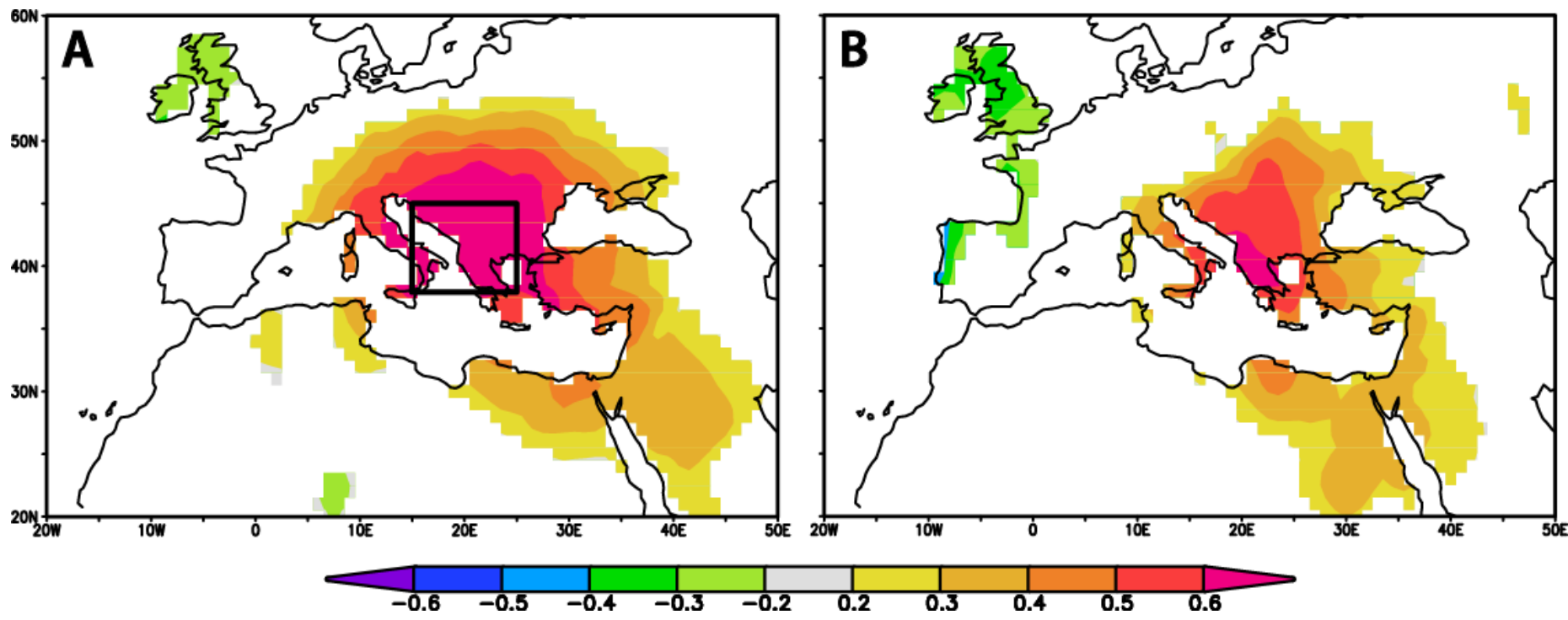

Figure 3. NEMED climate correlation maps. Pearson correlation map of (A) the NEMED master chronology and (B) a chronology including only the 28 MXD series that extend prior to 1700 with gridded $1^{\circ}$ CRU TS3.10 August-September (AS) temperature anomaly fields (1901-1980). The black box in (A) indicates the area over which AS temperatures were averaged for reconstruction. Correlation coefficients higher than 0.3 are significant at the $\mathrm{p}<0.01$ significance level. 


\section{NEMED Summer Temperature Reconstruction}

A PCA analysis including the $21 \mathrm{MXD}$ site chronologies from the species selected based on the climate-growth analysis (previous section) reveals that PCA1 explains $46.6 \%$ of the common variance and that the tree-ring series thus have a strong common signal. Of the 484 individual series contributing to this MXD compilation, 401 series were successfully crossdated and combined in a NEMED master chronology. The NEMED chronology shows strong common interannual variability $(\mathrm{RBAR}=0.509)$ and is well replicated with EPS values above 0.85 over the period $1675-1980$. A spatial correlation analysis (Figure 3A) reveals that the chronology is most strongly correlated with late summer (AS; similar for JAS) temperature $(r>0.6 ; 1901-1980)$ for the region $38-45^{\circ} \mathrm{N}$ and $15-25^{\circ} \mathrm{E}$. A similar analysis (Figure $3 \mathrm{~B}$ ), using a chronology based on only the 28 individual MXD series (from four sites in Italy and Greece) that extend back prior to 1700 , shows this spatial correlation pattern is robust even when using a data set with much reduced sample replication. I thus averaged gridded summer temperatures over this region and used the average AS and JAS temperature time series in the calibration and verification analysis.
Table 2. Calibration and verification statistics between the NEMED MXD chronology and August-September (AS) and July-September (JAS) instrumental temperatures.

\begin{tabular}{lllll}
\hline & Calibration & Verification & & \\
Period & $\mathrm{R}^{2}$ AS/JAS & $\mathrm{R}^{2}$ AS/JAS & RE AS/JAS & CE AS/JAS \\
\hline $1901-1940$ & $0.54 / 0.47$ & $0.76 / 0.71$ & $0.75 / 0.7$ & $0.75 / 0.7$ \\
$1941-1980$ & $0.76 / 0.71$ & $0.54 / 0.47$ & $0.43 / 0.34$ & $0.42 / 0.34$ \\
$1901-1980$ & $0.67 / 0.61$ & & & \\
\hline
\end{tabular}

Calibration and verification trials (Table 2) show that both temperature parameters (AS and JAS) can be skillfully reconstructed based on the NEMED MXD chronology, with $47 \%$ to $76 \%$ of the variance explained in the verification procedure and overall positive RE and CE statistics. More variance was explained for AS temperature compared to JAS temperature and RE and CE statistics were higher, indicating a stronger ability to capture low-frequency trends (Cook et al. 1994). I therefore used AS temperature (1901-1980) as the NEMED reconstruction target.

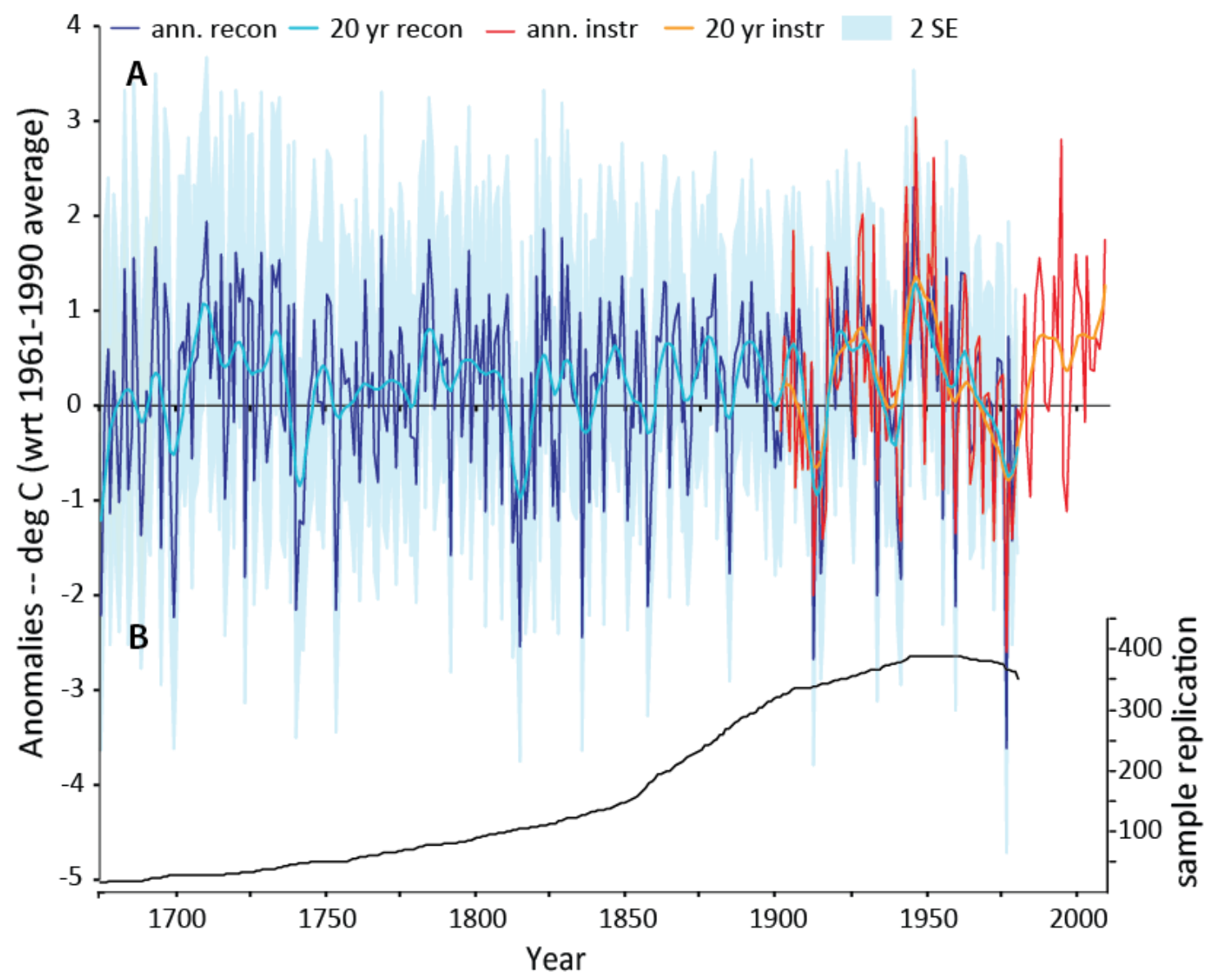

Figure 4. NEMED summer temperature reconstruction. (A) Annual and decadal-scale, tree-ring-based reconstruction (1675-1980; blue lines) and instrumental record (1901-2009; red and orange lines) of summer temperature deviations from a 1961-1990 average for the NEMED region. Decadal-scale time series are 20-year (cubic spline) smoothed series. Light blue zone indicates 2SE uncertainty estimations (as explained in Methods section) for the annual tree-ring based reconstruction. (B) Sample replication for the NEMED master chronology. 
The late summer NEMED temperature reconstruction (Figure 4) shows four distinct cold periods: $1738-1745,1810-1818$, 1909-1916, and 1968-1980. The periods 1942-1954 and 17061715 are the warmest on record with 13 and 10 consecutive years of above-average summer temperatures, respectively. The 20th century warm and cold periods are also represented in the instrumental temperature record (Figure 4), which further shows a distinct positive post-1980 trend, with above-average temperatures occurring in 20 of the 25 summers since 1985 . The length of this recent warm period (so far) as well as the anomalies in individual years fall within their historical range. Pre-20th century periods of extreme temperatures correspond to cold and warm periods in two other regional summer temperature reconstructions (Figure 5). A

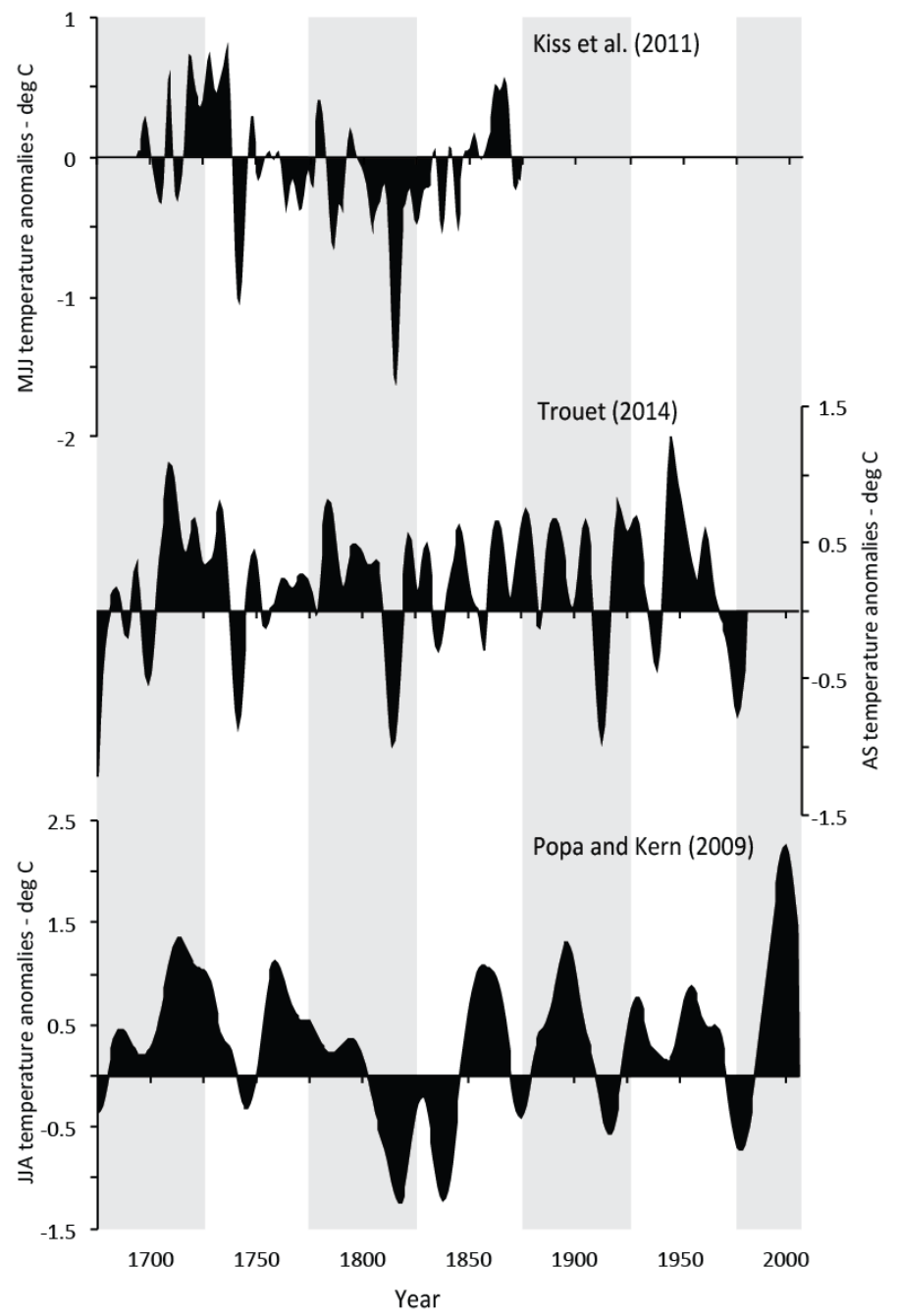

Figure 5. Comparison of NEMED temperature reconstructions. Decadally (20-year spline) smoothed time series of three NEMED temperature reconstructions: a document-based May-July temperature reconstruction (1694-1874) for western Hungary (Kiss et al. 2011); the NEMED August-September temperature reconstruction (Trouet 2014, this paper), and a tree-ring based June-August reconstruction (1163-2005) for northern Romania (Popa and Kern 2009). All temperature anomalies were calculated with regard to the 1961-1990 average. The locations of the Kiss et al. (2011) and Popa and Kern (2009) records are indicated in Figure 1. document-based May-July temperature reconstruction for western Hungary (Kiss et al. 2011) and a tree-ring based June-August reconstruction for northern Romania (Popa and Kern 2009) both show cold NEMED temperatures in the 1740s and the 1810s and warm temperatures in the first half of the 18th century. Moreover, the two 20th century cold periods, as well as a pre-1680 cold period, are also reflected in the Popa and Kern (2009) record.

\section{DISCUSSION}

August temperature is a driver of interannual MXD variability in seven out of the eight NEMED conifer species analyzed in this study (Figure 2). This result has previously been found for one of the species (Trouet et al. 2012; Klesse et al. 2014) as well as for spruce in NEMED (Kern and Popa 2009; Levanic et al. 2009) and can be explained by the influence of August temperature on cell-wall thickening and lignification processes (Deslauriers et al. 2008). The seasonality of the climate signal in NEMED MXD series, however, is species-dependent, with only four species also sensitive to temperature variability in September (Figure 2). Speciesspecific growth responses to climate have previously been found for a wide range of tree species growing under comparable environmental conditions across the European continent (Babst et al. 2013). In high-elevation NEMED trees, latewood formation occurs between mid to late July and early to late September (Rossi et al. 2006; Deslauriers et al. 2008), but the lignification of the outermost row of latewood tracheids can extend considerably beyond cessation of cambial activity (Gricar et al. 2005) and can explain the relation between MXD and September temperatures in some species. PINI is the only species in this study for which MXD measurements are more sensitive to (August) precipitation than to temperature (Figure 2). PINI is a drought-sensitive tree species (Lebourgeois 2000; Martín-Benito et al. 2008) and its tree-ring width measurements have previously been used to reconstruct NEMED precipitation (e.g. Poljansek et al. 2012; Levanič et al. 2013; Klesse et al. 2014). This result supports the findings of Esper et al. (2006) that at the driest Mediterranean sites and in the most drought-sensitive species, even at high elevation, MXD primarily records drought variability.

For the development of a regional-scale NEMED summer temperature reconstruction, I applied a new approach by combining 401 individual tree-ring series from 21 sites from a $15^{\circ}(\mathrm{E}-\mathrm{W})$ by $9^{\circ}(\mathrm{N}-\mathrm{S})$ region (Figure 1) into one NEMED master chronology. This approach is justified by the strong common variance between the MXD chronologies of the 21 sites (PCA1 explains $47 \%$ of the common variance), their common climate signal (Figure 2), and the fact that NEMED MXD is most sensitive to summer temperature, a climate parameter that shows strong spatial homogeneity over distances up to $2500 \mathrm{~km}$ (Jones et al. 1997; Büntgen et al. 2010b). I have been conservative in the crossdating of individual MXD series to develop the NEMED master chronology: all series that produced B-flags in COFECHA when crossdated to the master chronology - meaning that stronger correlations between the series and the master chronology were found for positions within a 
10 -year window than for the current dated position itself (GrissinoMayer 2001) - were removed from the master chronology. As a result, only $83 \%$ (401 out of 484) of the contributing series were retained for the master chronology, even if all 484 series were originally successfully crossdated at the site level-a requirement for the site chronologies to be included in the ITRDB. The main motivation for this conservative approach was that I used MXD data developed by other researchers and contributed by them to the ITRDB and thus did not have access to the original samples to verify and correct potential measurement or dating errors, here considered to be represented by B-flags. An added advantage of this approach is that only the series that show a strong and temporally robust common signal were retained in the master chronology and that site-specific signals were largely eliminated. This is reflected by the high RBAR (0.51) for the NEMED master chronology.

Another advantage of combining individual tree-ring series rather than site chronologies is that this potentially improves estimated EPS back in time and thus allows for reconstruction over a longer period of time. EPS reflects signal strength over time and generally only the portion of a chronology with EPS $>0.85$ is used for reconstruction purposes. When site chronologies are averaged to develop a master chronology, each chronology is cut off at the date when its EPS drops below 0.85, thus reducing the potential time series length of the regional master chronology. In the NEMED case, only one site chronology (Sierra de Crispo, Italy) has an EPS $>0.85$ prior to 1700 , whereas individual treering series from four sites were included in the NEMED master chronology prior to 1700 . By combining data from multiple sites, the common signal strength in the master chronology can be improved back in time.

To further improve the regional character of the NEMED late summer temperature reconstruction, I used averaged gridded instrumental temperature data from a broad region-including large parts of Albania, Bosnia and Herzegovina, Bulgaria, FYROM, Greece, southern Italy, Montenegro, Romania, and Serbia-as a target for reconstruction (Figure 3). Many NEMED meteorological station data lack appropriate homogenization (e.g. removal of urbanization effect; Peterson et al. 1998), and I therefore preferred to use gridded data to optimally represent climate variability at the regional scale as captured by the treering compilation. The spatial coherence of interannual variability in radiative forcing - and thus in temperature - over large geographical areas (Büntgen et al. 2010b) justifies this approach and its validity is confirmed by the spatial pattern of the temperature signal in the tree-ring data. The NEMED master chronology captures late summer temperature variability over a large region that extends beyond the area covered by the contributing tree-ring sites and includes large parts of central and eastern Europe, Turkey, Egypt, and the northern Arabian Peninsula (Figure 3). Moreover, the spatial correlation map shows a signature dipole pattern with negative temperature correlations over the British Isles that reflects the influence of the summer North Atlantic Oscillation (sNAO; Folland et al. 2009; Trouet et al. 2012). As a result of the broad spatial signature of interannual temperature variability, the NEMED summer temperature reconstruction shares cold and warm events and periods with other regional and global temperature records.

Some of the warmest (1940s) and coldest (1910s) periods, as well as warmest (1945) and coldest (1976) individual years in our NEMED reconstruction, occur during the 20th century and have also been recorded in regional instrumental summer temperature data (Repapis and Philandras 1988; Metaxas et al. 1991; Xoplaki et al. 2003a). The 1945 heat wave corresponds to the driest year on record for the Bulgarian lowlands (Koleva and Alexandrov 2008) and the 1940s summer warming has been reported as a period of widespread summer drought in Bulgaria (Tran et al. 2002; Alexandrov et al. 2004; Koleva and Alexandrov 2008) and throughout Europe (Briffa et al. 1994). The cold summers of 1959 and 1976 are recorded as cold extremes throughout the Mediterranean (Xoplaki et al. 2003b; Trouet et al. 2012; Klesse et al. 2014). It is worth noting, however, that 1976 was one of the driest and hottest summers on record in central and western Europe (Zaidman et al. 2002), and in the British Isles in particular (Jones and Conway 1997) and thus is a strong manifestation of the sNAO dipole pattern (Folland et al. 2009; Trouet et al. 2012).

Regional climatic extremes prior to the 20th century that are reflected in our NEMED reconstruction include the cold summer of 1699, which was characterized by year-round snow cover over the Cretan mountains and poor harvest in Thessaly (Xoplaki et al. 2001). One of the coldest NEMED decades, 1810-1818, occurs as a cold decade in many other regional (Figure 5 and Klesse et al. 2014), central European (Büntgen et al. 2006; Zumbühl et al. 2008; Böhm et al. 2010), and large-scale (Briffa et al. 1998; Franke et al. 2011) summer temperature records. The extreme cold during this decade can be explained by a combination of low solar irradiance (Dalton minimum, AD 1790-1830, Stuiver 1961; Bard et al. 2000) and the cooling effect of two major volcanic eruptions (Dai et al. 1991; Wagner and Zorita 2005), including the well-documented 1815 Tambora eruption (Stothers 1984; Briffa et al. 1998; Robertson et al. 2001; Oppenheimer 2003). Other manifestations of external (volcanic and solar) forcing of NEMED temperature variability include the 1675-1680 cold period that occurred during the Maunder solar minimum (Eddy 1976) and volcanic eruptions in 1835 (Cosiguina), 1883 (Krakatoa), and 1912 (Novarupta) that resulted in below-average NEMED summer temperatures.

Other years of European-wide extreme weather cannot easily be attributed to external drivers. A prominent example is the year 1740, which was characterized by extreme cold throughout Europe (Shabalova and van Engelen 2003; Jones and Briffa 2006; IPCC 2013) and in New England (Perley 1891), leading e.g. to widespread famine in Ireland (Dickson 1997; Engler et al. 2013), and is one of the coldest years in our NEMED reconstruction. 


\section{CONCLUSIONS}

By compiling MXD measurements from 21 sites, I developed a NEMED summer temperature reconstruction that covers the period AD 1675-1980. Cold and warm extremes and decades in this NEMED reconstruction correspond to regional-scale instrumental data sets and reconstructions. Some extreme periods (e.g. 1810s) reflect European-wide or even global-scale climate conditions and can be explained by volcanic and/or solar forcing. Other extremes, however, are strictly regional in scope (e.g. cool summer of 1976). The regional NEMED summer reconstruction thus contributes to an improved understanding of regional (e.g. sNAO) vs. global-scale (i.e. external) drivers of past climate variability. All but one of the NEMED sites used in this reconstruction were sampled in the early 1980s and updates of these site collections are urgently needed to study the influence of recent anthropogenic NEMED climate forcing in this context.

\section{ACKNOWLEDGMENTS}

This study was supported by the National Science Foundation (CAREER Award AGS-1349942). I would like to thank D. Frank, S. Klesse, and M. Panayotov for their useful input.

\section{REFERENCES}

Akkemik, U., and A. Aras, 2005. Reconstruction (1689-1994 AD) of AprilAugust precipitation in the southern part of central Turkey. International Journal of Climatology 25(4):537-548.

Alcamo, J., M. Florke, and M. Marker, 2007. Future long-term changes in global water resources driven by socio-economic and climatic changes. Hydrological Sciences Journal-Journal des Sciences Hydrologiques 52(2):247-275.

Alexandrov, V., M. Schneider, E. Koleva, and J. M. Moisselin, 2004. Climate variability and change in Bulgaria during the 20th century. Theoretical and Applied Climatology 79(3-4):133-149.

Babst, F., B. Poulter, V. Trouet, K. Tan, B. Neuwirth, R. Wilson, M. Carrer, M. Grabner, W. Tegel, T. Levanic, M. Panayotov, C. Urbinati, O. Bouriaud, P. Ciais, and D. Frank, 2013. Site- and species-specific responses of forest growth to climate across the European continent. Global Ecology and Biogeography 22(6):706-717.

Bard, E., G. Raisbeck, F. Yiou, and J. Jouzel, 2000. Solar irradiance during the last 1200 years based on cosmogenic nuclides. Tellus B 52(3):985-992.

Barriendos, M., and F. S. Rodrigo, 2006. Study of historical flood events on Spanish rivers using documentary data. Hydrological Sciences Journal-Journal des Sciences Hydrologiques 51(5):765-783.

Bartolini, G., V. di Stefano, G. Maracchi, and S. Orlandini, 2012. Mediterranean warming is especially due to summer season. Evidences from Tuscany (central Italy). Theoretical and Applied Climatology 107(1-2):279-295.

Böhm, R., P. D. Jones, J. Hiebl, D. Frank, M. Brunetti, and M. Maugeri, 2010. The early instrumental warm-bias: A solution for long central European temperature series 1760-2007. Climatic Change 101(1-2):41-67.

Briffa, K. R., P. D. Jones, and F. H. Schweingruber, 1992. Tree-ring density reconstructions of summer temperature patterns across western North America since 1600. Journal of Climate 5(7):735-754.

Briffa, K. R., P. D. Jones, and M. Hulme, 1994. Summer moisture variability across Europe, 1892-1991 - An analysis based on the Palmer Drought Severity Index. International Journal of Climatology 14(5):475-506.

Briffa, K. R., P. D. Jones, F. H. Schweingruber, and T. J. Osborn, 1998. Influence of volcanic eruptions on Northern Hemisphere summer temperature over the past 600 years. Nature 393(6684):450-455.

Büntgen, U., D. C. Frank, D. Nievergelt, and J. Esper, 2006. Summer temperature variations in the European Alps, AD 755-2004. Journal of Climate 19(21): $5606-5623$.
Büntgen, U., D. Frank, H. Grudd, and J. Esper, 2008. Long-term summer temperature variations in the Pyrenees. Climate Dynamics 31(6):615-631.

Büntgen, U., D. Frank, V. Trouet, and J. Esper, 2010a. Diverse climate sensitivity of Mediterranean tree-ring width and density. Trees - Structure and Function 24(2):261-273.

Büntgen, U., J. Franke, D. Frank, R. Wilson, F. J. Gonzalez-Rouco, and J. Esper, 2010b. Assessing the spatial signature of European climate reconstructions. Climate Research 41(2):125-130.

Camuffo, D., C. Bertolin, M. Barriendos, F. Dominguez-Castro, C. Cocheo, S. Enzi, M. Sghedoni, A. della Valle, E. Garnier, M. J. Alcoforado, E. Xoplaki, J. Luterbacher, N. Diodato, M. Maugeri, M. F. Nunes, and R. Rodriguez, 2010. 500-year temperature reconstruction in the Mediterranean Basin by means of documentary data and instrumental observations. Climatic Change 101(1-2):169-199.

Chang, H., C. G. Knight, M. P. Staneva, and D. Kostov, 2002. Water resource impacts of climate change in southwestern Bulgaria. GeoJournal 57:159-168.

Chenoweth, J., P. Hadjinicolaou, A. Bruggeman, J. Lelieveld, Z. Levin, M. A. Lange, E. Xoplaki, and M. Hadjikakou, 2011. Impact of climate change on the water resources of the eastern Mediterranean and Middle East region: Modeled 21st century changes and implications. Water Resources Research 47:W06506, doi:10.1029/2010WR010269.

Cook, E. R., 1985. A Time-Series Analysis Approach to Tree-Ring Standardization. Ph.D. thesis, University of Arizona; $171 \mathrm{pp.}$

Cook, E. R., and K. Peters, 1981. The smoothing spline: A new approach to standardizing forest interior tree-ring width series for dendroclimatic studies. Tree-Ring Bulletin 41:45-53.

Cook, E. R., and K. Peters, 1997. Calculating unbiased tree-ring indices for the study of climatic and environmental change. Holocene 7(3):361-370.

Cook, E. R., K. R. Briffa, and P. D. Jones, 1994. Spatial regression methods in dendroclimatology - A review and comparison of 2 techniques. International Journal of Climatology 14(4):379-402.

Csernus-Molnár, I., A. Kiss, and E. Pócsik, 2014. 18th-century daily measurements and weather observations in the SE-Carpathian Basin: A preliminary analysis of the Timişoara series (1780-1803). Journal of Environmental Geography 7(1-2):1-9.

Dai, J., E. Mosley-Thompson, and L. G. Thompson, 1991. Ice core evidence for an explosive tropical volcanic eruption 6 years preceding Tambora. Journal of Geophysical Research: Atmospheres 96(D9):17,361-17,366.

Deslauriers, A., S. Rossi, T. Anfodillo, and A. Saracino, 2008. Cambial phenology, wood formation and temperature thresholds in two contrasting years at high altitude in southern Italy. Tree Physiology 28(6):863-871.

Dickson, D., 1997. Arctic Ireland: The Extraordinary Story of the Great Frost and Forgotten Famine of 1740-1741. White Row Press, Belfast, UK.

Diffenbaugh, N. S., J. S. Pal, F. Giorgi, and X. J. Gao, 2007. Heat stress intensification in the Mediterranean climate change hotspot. Geophysical Research Letters 34(11):L11706, doi:10.1029/2007g1030000.

Dominguez-Castro, F., J. I. Santisteban, M. Barriendos, and R. Mediavilla, 2008. Reconstruction of drought episodes for central Spain from rogation ceremonies recorded at the Toledo Cathedral from 1506 to 1900: A methodological approach. Global and Planetary Change 63(2-3):230-242.

Eddy, J., 1976. The Maunder minimum. Science 192(4245):1189-1202.

Engler, S., J. Luterbacher, F. Mauelshagen, and J. Werner, 2013. The Irish famine of 1740-1741: Causes and effects. Climate of the Past Discussions 9(1):11611179 .

Esper, J., U. Buntgen, D. Frank, D. Nievergelt, K. Treydte, and A. Verstege, 2006. Multiple tree-ring parameters from Atlas cedar (Morocco) and their climatic signal. Tree Rings in Archaeology, Climatology, and Ecology (TRACE) 4:46-55.

Esper, J., D. Frank, U. Buntgen, A. Verstege, J. Luterbacher, and E. Xoplaki, 2007. Long-term drought severity variations in Morocco. Geophysical Research Letters 34(17):L17702, doi:10.1029/2007g1030844.

Felis, T., and N. Rimbu, 2010. Mediterranean climate variability documented in oxygen isotope records from northern Red Sea corals-A review. Global and Planetary Change 71(3-4):232-241.

Folland, C. K., J. Knight, H. W. Linderholm, D. Fereday, S. Ineson, and J. W. Hurrell, 2009. The summer North Atlantic Oscillation: Past, present, and future. Journal of Climate 22(5):1082-1103. 
Founda, D., and C. Giannakopoulos, 2009. The exceptionally hot summer of 2007 in Athens, Greece - A typical summer in the future climate? Global and Planetary Change 67(3-4):227-236.

Founda, D., K. H. Papadopoulos, M. Petrakis, C. Giannakopoulos, and P. Good, 2004. Analysis of mean, maximum, and minimum temperature in Athens from 1897 to 2001 with emphasis on the last decade: Trends, warm events, and cold events. Global and Planetary Change 44(1-4):27-38.

Frank, D. C., J. Esper, C. C. Raible, U. Büntgen, V. Trouet, B. Stocker, and F. Joos, 2010. Ensemble reconstruction constraints on the global carbon cycle sensitivity to climate. Nature 463(7280):527-530.

Franke, J., J. Fidel Gonzalez-Rouco, D. Frank, and N. E. Graham, 2011. 200 years of European temperature variability: Insights from and tests of the proxy surrogate reconstruction analog method. Climate Dynamics 37(1-2):133-150.

Giannakopoulos, C., P. Le Sager, M. Bindi, M. Moriondo, E. Kostopoulou, and C. M. Goodess, 2009. Climatic changes and associated impacts in the Mediterranean resulting from a 2 degrees $\mathrm{C}$ global warming. Global and Planetary Change 68(3):209-224.

Gibelin, A. L., and M. Deque, 2003. Anthropogenic climate change over the Mediterranean region simulated by a global variable resolution model. Climate Dynamics 20(4):327-339.

Giles, B. D., and A. A. Flocas, 1984. Air-temperature variations in Greece. 1. Persistence, trend, and fluctuations. Journal of Climatology 4(5):531-539.

Giorgi, F., 2006. Climate change hot-spots. Geophysical Research Letters 33(8):L08707, doi:10.1029/2006gl025734.

Gricar, J., K. Cufar, P. Oven, and U. Schmitt, 2005. Differentiation of terminal latewood tracheids in silver fir during autumn. Annals of Botany 95(6):959-965.

Grissino-Mayer, H. D., 2001. Crossdating accuracy: A manual and tutorial for the computer program COFECHA. Tree-Ring Research 57(2):205-221.

Grissino-Mayer, H. D., and H. C. Fritts, 1997. The International Tree-Ring Data Bank: An enhanced global database serving the global scientific community. Holocene 7(2):235-238

Hegerl, G. C., T. J. Crowley, W. T. Hyde, and D. J. Frame, 2006. Climate sensitivity constrained by temperature reconstructions over the past seven centuries. Nature 440(7087):1029-1032.

Hertig, E., S. Seubert, A. Paxian, G. Vogt, H. Paeth, and J. Jacobeit, 2013. Changes of total versus extreme precipitation and dry periods until the end of the twenty-first century: Statistical assessments for the Mediterranean area. Theoretical and Applied Climatology 111(1-2):1-20.

IPCC, 2013. Climate Change 2013: The Physical Science Basis. Contribution of Working Group I to the Fifth Assessment Report of the Intergovernmental Panel on Climate Change, edited by T. F. Stocker, D. Qin, G.-K. Plattner, M. Tignor, S. K. Allen, J. Boschung, A. Nauels, Y. Xia, V. Bex, and P. M. Midgley, Cambridge University Press, Cambridge.

Jones, P. D., and K. R. Briffa, 2006. Unusual climate in Northwest Europe during the period 1730 to 1745 based on instrumental and documentary data. Climatic Change 79(3-4):361-379.

Jones, P. D., and D. Conway, 1997. Precipitation in the British Isles: An analysis of area-average data updated to 1995. International Journal of Climatology 17(4):427-438

Jones, P. D., T. J. Osborn, and K. R. Briffa, 1997. Estimating sampling errors in large-scale temperature averages. Journal of Climate 10(10):2548-2568.

Jones, P. D., K. R. Briffa, T. J. Osborn, J. M. Lough, T. D. van Ommen, B. M. Vinther, J. Luterbacher, E. R. Wahl, F. W. Zwiers, M. E. Mann, G. A. Schmidt, C. M. Ammann, B. M. Buckley, K. M. Cobb, J. Esper, H. Goosse, N. Graham, E. Jansen, T. Kiefer, C. Kull, M. Kuettel, E. Mosley-Thompson, J. T. Overpeck, N. Riedwyl, M. Schulz, A. W. Tudhope, R. Villalba, H. Wanner, E. Wolff, and E. Xoplaki, 2009. High-resolution palaeoclimatology of the last millennium: A review of current status and future prospects. Holocene 19(1):3-49.

Kern, Z., and I. Popa, 2009. Assessing temperature signal in X-ray densitometric data of Norway spruce and the earliest instrumental record from the southern Carpathians. Journal of Environmental Geography 2(3-4):15-22.

Kiss, A., R. Wilson, and I. Bariska, 2011. An experimental 392-year documentary-based multi-proxy (vine and grain) reconstruction of May-July temperatures for Köszeg, West-Hungary. International Journal of Biometeorology 55(4):595-611.

Klesse, S., M. Ziehmer, V. Trouet, and D. C. Frank, 2014. Synoptic drivers of 400 years of summer temperature and precipitation variability on Mt. Olympus,
Greece. Climate Dynamics doi:10.1007/s00382-014-2313-3.

Knowlton, K., M. Rotkin-Ellman, G. King, H. G. Margolis, D. Smith, G. Solomon, R. Trent, and P. English, 2009. The 2006 California heat wave: Impacts on hospitalizations and emergency department visits. Environmental Health Perspectives 117(1):61-67.

Koleva, E., and V. Alexandrov, 2008. Drought in the Bulgarian low regions during the 20th century. Theoretical and Applied Climatology 92(1-2):113-120.

Kostopoulou, E., and P. D. Jones, 2005. Assessment of climate extremes in the Eastern Mediterranean. Meteorology and Atmospheric Physics 89(1-4):6985

Lebourgeois, F., 2000. Climatic signals in earlywood, latewood and total ring width of Corsican pine from western France. Annals of Forest Science 57(2):155-164.

Lelieveld, J., P. Hadjinicolaou, E. Kostopoulou, J. Chenoweth, M. El Maayar, C. Giannakopoulos, C. Hannides, M. A. Lange, M. Tanarhte, E. Tyrlis, and E. Xoplaki, 2012. Climate change and impacts in the Eastern Mediterranean and the Middle East. Climatic Change 114(3-4):667-687.

Levanic, T., J. Gricar, M. Gagen, R. Jalkanen, N. J. Loader, D. McCarroll, P. Oven, and I. Robertson, 2009. The climate sensitivity of Norway spruce [Picea abies (L.) Karst.] in the southeastern European Alps. Trees - Structure and Function 23(1):169-180.

Levanič, T., I. Popa, S. Poljanšek, and C. Nechita, 2013. A 323-year long reconstruction of drought for SW Romania based on black pine (Pinus nigra) treering widths. International Journal of Biometeorology 57(5):703-714.

Mann, M. E., Z. Zhang, S. Rutherford, R. S. Bradley, M. K. Hughes, D. Shindell, C. Ammann, G. Faluvegi, and F. Ni, 2009. Global signatures and dynamical origins of the Little Ice Age and Medieval Climate Anomaly. Science 326(5957):1256-1260.

Martín-Benito, D., P. Cherubini, M. del Río, and I. Cañellas, 2008. Growth response to climate and drought in Pinus nigra Arn. trees of different crown classes. Trees 22(3):363-373.

Meehl, G. A., and C. Tebaldi, 2004. More intense, more frequent, and longer lasting heat waves in the 21st century. Science 305(5686):994-997.

Metaxas, D. A., A. Bartzokas, and A. Vitsas, 1991. Temperature fluctuations in the Mediterranean area during the last 120 years. International Journal of Climatology 11(8):897-908.

Mitchell, T. D., and P. D. Jones, 2005. An improved method of constructing a database of monthly climate observations and associated high-resolution grids. International Journal of Climatology 25(6):693-712.

Moriondo, M., P. Good, R. Durao, M. Bindi, C. Giannakopoulos, and J. CorteReal, 2006. Potential impact of climate change on fire risk in the Mediterranean area. Climate Research 31(1):85-95.

Nastos, P. T., C. M. Philandras, J. Kapsomenakis, and K. Eleftheratos, 2011. Variability and trends of mean maximum and mean minimum air temperature in Greece from ground-based observations and NCEP-NCAR reanalysis gridded data. International Journal of Remote Sensing 32(21):6177-6192.

Nicault, A., S. Alleaume, S. Brewer, M. Carrer, P. Nola, and J. Guiot, 2008. Mediterranean drought fluctuation during the last 500 years based on tree-ring data. Climate Dynamics 31(2-3):227-245.

Oppenheimer, C., 2003. Climatic, environmental and human consequences of the largest known historic eruption: Tambora volcano (Indonesia) 1815. Progress in Physical Geography 27(2):230-259.

PAGES $2 \mathrm{k}$ Consortium, 2013. Continental-scale temperature variability during the past two millennia. Nature Geoscience 6(5):339-346.

Panayotov, M., P. Bebi, V. Trouet, and S. Yurukov, 2010. Climate signal in treering chronologies of Pinus peuce and Pinus heldreichii from the Pirin Mountains in Bulgaria. Trees - Structure and Function 24(3):479-490.

Pauling, A., J. Luterbacher, C. Casty, and H. Wanner, 2006. Five hundred years of gridded high-resolution precipitation reconstructions over Europe and the connection to large-scale circulation. Climate Dynamics 26(4):387-405.

Perley, S., 1891. Historic Storms of New England. Salem Press, Salem, MA.

Peterson, T., D. Easterling, T. Karl, P. Groisman, N. Nicholls, N. Plummer, S. Torok, I. Auer, R. Boehm, D. Gullett, L. Vincent, R. Heino, H. Tuomenvirta, O. Mestre, T. Szentimrey, J. Salinger, E. Forland, I. Hanssen-Bauer, H. Alexandersson, P. Jones, and D. Parker, 1998. Homogeneity adjustments of in situ atmospheric climate data: A review. International Journal of Climatology 18(13):1493-1517. 
Philandras, C. M., P. T. Nastos, and C. C. Repapis, 2008. Air temperature variability and trends over Greece. Global Nest Journal 10(2):273-285.

Piervitali, E., and M. Colacino, 2001. Evidence of drought in western Sicily during the period 1565-1915 from liturgical offices. Climatic Change 49(1-2):225238.

Poljansek, S., D. Ballian, T. A. Nagel, and T. Levanic, 2012. A 435-year long European black pine (Pinus nigra) chronology for the central-western Balkan region. Tree-Ring Research 68(1):31-44.

Popa, I., and Z. Kern, 2009. Long-term summer temperature reconstruction inferred from tree-ring records from the Eastern Carpathians. Climate Dynamics 32(7-8):1107-1117.

Repapis, C. C., and C. M. Philandras, 1988. A note on the air-temperature trends of the last 100 years as evidenced in the eastern Mediterranean time-series. Theoretical and Applied Climatology 39(2):93-97.

Robertson, A., J. Overpeck, D. Rind, E. Mosley-Thompson, G. Zielinski, J. Lean, D. Koch, J. Penner, I. Tegen, and R. Healy, 2001. Hypothesized climate forcing time series for the last 500 years. Journal of Geophysical Research-Atmospheres 106(D14):14,783-14,803.

Rossi, S., A. Deslauriers, T. Anfodillo, H. Morin, A. Saracino, R. Motta, and M. Borghetti, 2006. Conifers in cold environments synchronize maximum growth rate of tree-ring formation with day length. New Phytologist 170(2):301-310.

Rudzka, D., F. McDermott, and M. Suric, 2012. A late Holocene climate record in stalagmites from Modric Cave (Croatia). Journal of Quaternary Science 27(6):585-596.

Schroter, D., W. Cramer, R. Leemans, I. C. Prentice, M. B. Araujo, N. W. Arnell, A. Bondeau, H. Bugmann, T. R. Carter, C. A. Gracia, A. C. de la Vega-Leinert, M. Erhard, F. Ewert, M. Glendining, J. I. House, S. Kankaanpaa, R. J. T. Klein, S. Lavorel, M. Lindner, M. J. Metzger, J. Meyer, T. D. Mitchell, I. Reginster, M. Rounsevell, S. Sabate, S. Sitch, B. Smith, J. Smith, P. Smith, M. T. Sykes, K. Thonicke, W. Thuiller, G. Tuck, S. Zaehle, and B. Zierl, 2005. Ecosystem service supply and vulnerability to global change in Europe. Science 310(5752):1333-1337.

Schweingruber, F. H., H. C. Fritts, O. U. Braeker, L. G. Drew, and E. Schaer, 1978. The X-ray technique as applied to dendrochronology. Tree-Ring Bulletin 38:61-91.

Seim, A., U. Buntgen, P. Fonti, H. Haska, F. Herzig, W. Tegel, V. Trouet, and K. Treydte, 2012. The paleoclimatic value of a millennium-long tree-ring chronology from Albania. Climate Research 51:217-228.

Serre-Bachet, F., 1994. Middle-ages temperature reconstructions in Europe, a focus on northeastern Italy. Climatic Change 26(2-3):213-224.

Shabalova, M. V., and A. G. V. van Engelen, 2003. Evaluation of a reconstruction of winter and summer temperatures in the low countries, AD 764-1998. Climatic Change 58(1-2):219-242.

Smoyer-Tomic, K. E., R. Kuhn, and A. Hudson, 2003. Heat wave hazards: An overview of heat wave impacts in Canada. Natural Hazards 28(2-3):463-485.

Stothers, R. B., 1984. The great Tambora eruption in 1815 and its aftermath. Science 224(4654):1191-1198.

Stuiver, M., 1961. Variations in radiocarbon concentration and sunspot activity. Journal of Geophysical Research 66(1):273-276.

Tardif, J., J. J. Camarero, M. Ribas, and E. Gutierrez, 2003. Spatiotemporal variability in tree growth in the Central Pyrenees: Climatic and site influences. Ecological Monographs 73(2):241-257.

Toreti, A., F. Desiato, G. Fioravanti, and W. Perconti, 2010. Seasonal temperatures over Italy and their relationship with low-frequency atmospheric circulation patterns. Climatic Change 99(1-2):211-227.

Touchan, R., G. Funkhouser, M. K. Hughes, and N. Erkan, 2005a. Standardized precipitation index reconstructed from Turkish tree-ring widths. Climatic Change 72(3):339-353.

Touchan, R., E. Xoplaki, G. Funkhouser, J. Luterbacher, M. K. Hughes, N. Erkan, U. Akkemik, and J. Stephan, 2005b. Reconstructions of spring/summer precipitation for the Eastern Mediterranean from tree-ring widths and its connection to large-scale atmospheric circulation. Climate Dynamics 25(1):75-98.

Touchan, R., U. Akkemik, M. K. Hughes, and N. Erkan, 2007. May-June precipitation reconstruction of Southwestern Anatolia, Turkey during the last 900 years from tree rings. Quaternary Research 68(2):196-202.

Touchan, R., K. J. Anchukaitis, D. M. Meko, S. Attalah, C. Baisan, and A. Aloui, 2008a. Long term context for recent drought in northwestern Africa. Geophysical Research Letters 35(13):L13705, doi:10.1029/2008gl034264

Touchan, R., D. M. Meko, and A. Aloui, 2008b. Precipitation reconstruction for Northwestern Tunisia from tree rings. Journal of Arid Environments 72(10):1887-1896.

Tran, L., C. G. Knight, and V. Wesner, 2002. Drought in Bulgaria and atmospheric synoptic conditions over Europe. GeoJournal 57:149-157.

Trouet, V., and G. J. van Oldenborgh, 2013. KNMI Climate Explorer: A webbased research tool for high-resolution paleoclimatology. Tree-Ring Research 69(1):3-13.

Trouet, V., M. Panayotov, A. Ivanova, and D. Frank, 2012. A Pan-European summer teleconnection mode recorded by a new temperature reconstruction from the eastern Mediterranean (1768-2008). The Holocene 22(8):887-898.

Vakarelov, I., S. Mirtchev, E. Kachaunova, and N. Simeonova, 2001. Reconstruction of summer air temperatures by dendrochronological analysis of Macedonian pine (Pinus peuce Griseb.) in Pirin mountains (Southeast Bulgaria). Forestry Ideas 1-4:16-26.

Wagner, S., and E. Zorita, 2005. The influence of volcanic, solar and $\mathrm{CO}_{2}$ forcing on the temperatures in the Dalton minimum (1790-1830): A model study. Climate Dynamics 25(2-3):205-218.

Wigley, T. M. L., K. R. Briffa, and P. D. Jones, 1984. On the average value of correlated time-series, with applications in dendroclimatology and hydrometeorology. Journal of Climate and Applied Meteorology 23(2):201-213.

Xoplaki, E., P. Maheras, and J. Luterbacher, 2001. Variability of climate in Meridional Balkans during the periods $1675-1715$ and $1780-1830$ and its impact on human life. Climatic Change 48(4):581-615.

Xoplaki, E., J. F. Gonzalez-Rouco, D. Gyalistras, J. Luterbacher, R. Rickli, and H. Wanner, 2003a. Interannual summer air temperature variability over Greece and its connection to the large-scale atmospheric circulation and Mediterranean SSTs 1950-1999. Climate Dynamics 20(5):537-554.

Xoplaki, E., J. F. Gonzalez-Rouco, J. Luterbacher, and H. Wanner, 2003b. Mediterranean summer air temperature variability and its connection to the largescale atmospheric circulation and SSTs. Climate Dynamics 20(7-8):723-739.

Zaidman, M. D., H. G. Rees, and A. R. Young, 2002. Spatio-temporal development of streamflow droughts in northwest Europe. Hydrology and Earth System Sciences 6(4):733-751.

Zumbühl, H. J., D. Steiner, and S. U. Nussbaumer, 2008. 19th century glacier representations and fluctuations in the central and western European Alps: An interdisciplinary approach. Global and Planetary Change 60(1-2):42-57. 